\title{
Autism spectrum disorders A resource for ASD information on the Web
}

A utism Spectrum Disorders (ASD) is a collective term given to developmental disabilities that impair the way that individuals interact and communicate with others. ASD includes Autism, Asperger's Syndrome, pervasive developmental disorder not otherwise specified (PDD-NOS), and others as defined by the DSM-IV (Diagnostic and Statistical Manual of Mental Disorders). Asperger's Syndrome is sometimes used synonymously with high functioning autism to distinguish people on the spectrum who have a stronger command of language.

Autism was first identified in 1943 by two physicians working on both sides of the Atlantic; Leo Kanner of Johns Hopkins University coined the phrase autism, while Hans Asperger worked in Austria. Originally thought to be rare (one case in 2,500 children), recent estimates put this number closer to one in 500. This "epidemic" could be caused by a number of factors, including controversial ones (MMR vaccines, environmental toxins, genetics, etc.) to more safe ones (better diagnosis of ASD and recognizing verbal children with autism).

Not surprisingly, the increase in the number of cases of ASD has coincided with a great deal of attention in the national media (with cover stories in both Time and Newsweek), a week-long special report on NBC and related networks, and a publishing boom that has seen the number of books published on ASD nearly double since the late 1990s.

With this increase in attention has also come an increase in the number of Web sites that have been developed. Many of these have been prepared by government agencies, organizations, and researchers. However, some of these sites have been developed and maintained by apparent "nonexperts." These may be parents or family members of people with autism. Though these accidental authors may lack the traditional credentials sought by librarians, they have become the biggest experts in the field by reading everything available on the subject. They have used their intellectual curiosity and desire to help others with ASD, practically garnering all the credentials that they need.

\section{The basics of ASD}

- Autism Fact Sheet from Child Development Institute. A great resource that includes a basic definition, common signs, diagnosis and causes, role of genetics, change over time, treatments, and links. Access: http://www.childdevelopmentinfo.com /disorders/autism_fact_sheet.shtml.

- What is Autism? From Autism Society of America (ASA). An excellent overview of autism and related disorders, including information on the prevalence of autism and links to discussions on common characteristics, causes, diagnosing, working with professionals, and a free online course on autism. Access: http://asa.convio.net/site/PageServer ?pagename $=$ whatisautism.

\section{General Web sites}

- Autism-INFO. Created in 1998 by Jenny and Brad Middlebrook, this site offers news,

Corey Seeman is assistant dean for resource and systems management at the University of Toledo, e-mail: corey. seeman@utoledo.edu

๑) 2005 Corey Seeman 
links, and information on autism for parents, teachers, therapists and doctors. One of its stated goals is to provide balanced information for families of recently diagnosed children. Sections of the site include: quick facts, medical issues, diet, books, news, applied behavior analysis (ABA) resources, action plans for newly diagnosed children, and conferences. Access: http://www. autisminfo.com.

- Autism Page of Patient Centered Guides. A list of printed material, online resources, and organizations taken from Appendix A of Mitzi Waltz's excellent book, Autistic Spectrum Disorders: Finding a Diagnosis and Getting Help (O'Reilly \& Associates, 2002). This resource is valuable, albeit a bit old. The main page for those resources, www. patientcenters.com/autism/, is also valuable and includes excerpts from the book. $A c$ cess: http://www.patientcenters.com/autism /news/resources.html.

- Autism Resources. Excellent general information resource on autism. Of note are the links to other sites, book listings, and "Advice to parents who discover their child is autistic." This includes messages from parents on what they would have liked to know when their child was diagnosed with autism. Access: http://www.autism-resources.com.

- Autism: The Hidden Epidemic? Links to articles and videos from the series of special reports from NBC News and MSNBC in February 2005. Included are numerous stories and personal accounts of the hopes, dreams, successes, and realities of living with ASD. (Another good source for media reports is $\mathrm{Na}-$ tional Public Radio at www.npr.org.) Access: http://www.msnbc.msn.com/id/6844737/.

\section{Narratives and key figures}

- Autism Real Stories and Tips. From the University of Kansas Beach Center on Disability, the "Real Stories and Tips" section includes narratives collected by staff or through Web site users. These stories are brief and help provide the many different faces of autism and related disorders. The site also includes links to other ASD resources on the Beach Center site and elsewhere. Access: http://www.beachcenter.org/stories/.

- The Geek Syndrome. Great article from Wired magazine by Steve Silberman on the rate of autism and Aperger's Syndrome among the children of Silicon Valley companies and Microsoft. Access: http://www.wired.com /wired/archive/9.12/aspergers_pr.html.

- Temple Grandin's Website. In the ASD community, Temple Grandin is a rock star. She is one of the most well-known adults with autism in the world. Diagnosed with autism as a young girl, Grandin went on to get her Ph.D. and become one of the leading figures in the study of livestock behavior and the design of humane cattle slaughter facilities. Access: http://www.templegrandin.com/.

- Tony Attwood's Web site. Tony Attwood is one of the leading figures working with ASD and has presented on the subject all over the world. This Web site includes many resources on Asperger's Syndrome and high functioning autism, including papers he has delivered, excerpts of current articles, workshop notes, links to Web resources, and other information. Access: http://www. tonyattwood.com.au/.

\section{Government sites}

- Centers for Disease Control and Prevention (CDC). The CDC's National Center on Birth Defects and Developmental Disabilities is a very good resource on autism. These pages have a number of resources that are useful, including a page describing autism, updated list of ASD projects at CDC, list of governmental projects at other federal and state agencies, resources, a great kids' page (geared to children between 4th and 6th grade) for teaching about ASD, and an excellent introductory section entitled "About Autism." Access: http://www.cdc.gov/ncbddd/dd /ddautism.htm.

- Interagency Autism Coordinating Committee (IACC). This committee coordinates autism research and other efforts within the Department of Health and Human Services. The National Institute of Mental Health at the National Institutes of Health has been des- 
ignated the lead for this activity. This page includes links to numerous reports of the activities of the committee and other government agencies. Access: http://www.nimh.nih.gov /autismiacc/index.cfm.

- National Institute of Mental Health (NIMH). An excellent basic source of information on ASD, NIMH gives a nice overview of the condition, signs and symptoms, treatment options, and local services. NIMH provides a link to the online document "Autism Spectrum Disorders (Pervasive Developmental Disorders)" (2004). Access. http://www.nimh.nih.gov/healthinformation /autismmenu.cfm.

- Principal Findings from the Epidemiology of Autism in California (M.I.N.D. Institute at University of California-Davis). Among many excellent state reports is this landmark study that was commissioned by the California Legislature and submitted on October 17, 2002. The study showed an increase of reported cases of autism of 273 percent from 1987 to 1998. This 70-page report is one of the most important documents examining the increased rate of ASD. Access: http://www.dds.ca.gov/autism/pdf/ study_final.pdf.

\section{Scientific and medical issues}

- Autism Network Resources for Physicians. Aimed at physicians, this site is valuable for parents and others looking for medical research on autism and ASD. This site includes links for autism research, medical treatment options, articles, reports, hearings, conferences, message boards and others. The "Autism Research and Related Links" section of the site has extensive resources for finding research being done in a number of areas on ASD, university-based programs, and a who's who of autism research. Access: http://home. san.rr.com/autismnet/index.html.

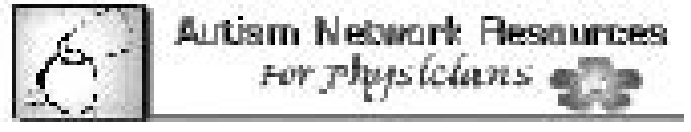

Cure Autism Now (CAN). CAN is an organization of parents, clinicians, and researchers working to promote understanding about autism and to fund research. The site includes a large number of links to other Web sites and resources that are

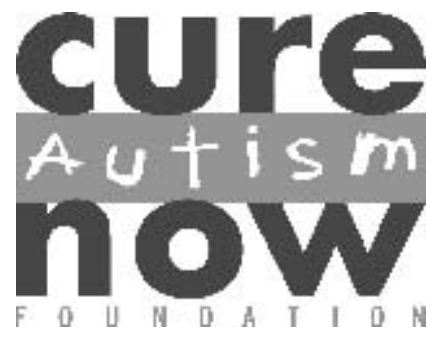
valuable for people studying autism. The "Science News" section will be of interest to people wishing to view the latest scientific research. Access: http://www.cureautismnow.org.

- National Alliance for Autism Research (NAAR). Founded in 1994, NAAR raises funds to support and accelerate biomedical research focusing on ASD. NAAR also publishes the "NAARRATIVE" newsletter, with updates on funding and research undertaken with their support. Current and back issues can be viewed on the Web site. Access: http://www.naar.org/.

\section{MMR and vaccines controversy}

- Autism Research Institute (ARI). ARI has been a leader in exploring the association between the MMR (Measles, Mumps, German Measles [Rubella]) vaccine and other drugs as the possible cause of autism. ARI is led by Bernard Rimland, one of the founders of the Autism Society of America and one of the most respected voices in the field. This site includes links to their case that the vaccine has a part in the spread of autism along with other strong information on autism. Access: http://www.autismwebsite.com/ari/vaccine /vaccine.htm.

- Centers for Disease Control and Prevention (Vaccines and Autism Theory). CDC has been an active proponent for the safety of the MMR vaccine and has conducted studies to examine the hypothesis that vaccines have a part in the cause of autism in children. While many organizations see this group as supporting the establishment view that there is no connection between the MMR vaccine and autism, they have produced a useful Web site for people examining this potential connection. This page includes many links to research papers, statistics, and other sources that examine the connection between the 
two. Access: http://www.cdc.gov/nip/vacsafe /concerns/autism/.

\section{Organizations}

- Autism Society of America (ASA). ASA is one of the leading organizations in the United States for promoting awareness and developing support for the autism community. ASA was founded in 1965 by a small group of parents working on a volunteer basis out of their homes and now has more than 20,000 members with nearly 200 chapters. See the section titled "Living with Autism," with sections on siblings, stress, and other demands on the family. Access: http://www. autism-society.org.

- Autism Society Ontario (ASO). ASO (Canada) has 29 chapters and provides infor-

\section{A The Voice of Autism. Autism Society of America,}

mation and advocacy for people with ASD throughout the Province of Ontario. The Web site is valuable for looking at services offered and available in Ontario. Of particular interest are the resources pages that offer sections on behavior, communication, diet, education, health, medication, Ontario services and agencies, publications, and research as well as a full listing of "1001" sites in alphabetical order. Access: http://www.autismsociety.on.ca/.

- Center for the Study of Autism (CSA). CSA is an advocate for biomedical interven- tions for children with autism. CSA works closely with the Autism Research Institute (Bernard Rimland) in San Diego, California. The site has many links to informational pages on definitions and different treatments. Access: http://www.autism.org.

- National Autistic Society. The leading ASD organization in the United Kingdom, this excellent site includes great information for families and siblings (through the link "Members of the family") and excellent personal narratives to get a better sense of what autism really looks like. Access: http://www. nas.org.uk/.

- Ontario Adult Autism Research and Support Network (OAARSN). A Web site specifically designed to address the needs of adults with ASD, the OAARSN is a unique resource. The site has five basic sections: autism information, organization/services, communications, autism-related Web sites, and unique resource documents. Of primary note are the unique resource documents that provide full-text resources, including regional organization newsletters, review of services, and excellent personal narratives of older children and adults with ASD in Ontario. These accounts are primarily in a section entitled "From the Front Lines ... Living With Autism" and provide an exceptional complementary online resource to personal narratives available in print. $A C$ cess: http://www.ont-autism.uoguelph.ca /newpage4.shtml. n

\section{PERIODICALS SERVICE COMPANY}

Are pleased to announce our recent journal stock management agreement with Kiluwer Academic Publishers. We have an agreement

to reprint all out of print volumes and issues for

Kluwer Academic Publishers B.V. journals.

For the list:- www.periodicals.com/kluwer.html

To sontad is:

11. Main Street, Germantowni, Nif 12526

Phone: 5185374700 Fax! 5185375899 E-mail. pseleperiodicals.com 